\title{
The Impact of Data and Information in the State's Economic Planning
}

\author{
Dr. Samir Salahaldin Hamdi \\ ${ }^{1}$ Department of health Administration, Cihan University, Erbil, Iraq
}

\begin{abstract}
It seems clear that the point of views prefer open economy and sectors vital roles in economy promotions, due to the changes and developments carried out around the world. This process needs human resource development and other boosting planning to get better economy development results.

The efforts should be organized to obtain the targets, such as state developed economy, providing more income resources, which lead to various resources, least not to rely on the sole economy source, such as petrol, which may finished at any time.

The development needs well organized plan of action in both types social system and capitalisms. This study presents the vital role of social system and capitalism plan of action in promoting the factors of 4P $\mathrm{s}$ in the marketing measurements. The study also shows the importance of planning in both socialist and capital mechanisms and the strategic promotions for better incomes and well organized economy development.
\end{abstract}

Keywords: Leadership, State, Planning, Business, Economy

\section{INTRODUCTION}

This guideline is used for International Journal of Research in Humanities and Social Sciences (IJRHSS). These are the manuscript preparation guidelines used as a standard template for all paper submissions of IJRHSS. Author must follow these instructions while preparing/modifying these guidelines.

Planning contributes positively in attaining the objectives of the business enterprise. The process of planning is one of the most important administrative steps, since it's been applied within the organization and in all levels of management [2].

It is an intellectual process of thinking in advance. It is a process of deciding the future on the series of events to follow. Planning is a process where a number of steps are to be taken to decide the future course of action.

It is a function of management exercised by the director or the administrative leader of the organization. Whereby a qualified state can be seen it its well organized actions, and a well-organized actions are part of a strong knowledge and to have a reliable knowledge there should be a faithful scientists [1].

Every former ancient civilizations and developed countries now are the result of the planning process. And here it is worth mentioning that the first planners in the history of ancient civilizations is (Hammurabi) of Babylonian civilization.

He has used and invented many of the modern scientific managerial terms which is used in organizations today as a general terms. Economic success and laws built up to the success of Babylonia. The Hammurabi codes established the success of Babylonia and besides Hammurabi's codes is perceived as the basis of some dimensions of legislation and planning system. Administrative operations of ancient people, reflecting very old part of the intelligence of mankind found their terminologies in 1900s with decorated and modernly organized management terms.

We could notice that this ancient society has formed a modern civilization in that period, despite the lack of resources. Whereas we can see the developing countries nowadays are at a standstill and they never move forward despite the humanitarian scientific development in all fields and the emergence 
of management science. So when the state is a planning state, it will reach a state of development, productivity and will eventually reach a state of growth and high income as a result of a large national output and all that is owed to the strategy of economic planning [1][2].

To highlight the objectives of this research it will address three topics:

- First part: the need for planning within its concepts in economic development.

- The second part: economic planning and its relationship to information and data standard base models.

- The third part: the role of the state in economic planning process.

\section{RESEARCH METHODOLOGY}

Planning precedes other functions in the management process. Certainly, setting of goals to be achieved and lines of action to be followed precedes the organization, direction, supervision and control. This research studies the role of economic planning in the process of restructuring the development economics using the descriptive, logical and theoretical analysis, because they provide facts and information on the subject, as well as the study of the experiences of some developed countries and the developing countries that have succeeded in the planning and directing process.

\section{Research Problem}

Currently, the world depends heavily on oil, to meet its energy needs. However, the utilization of this energy sources has a drastic impact of the economy in the future. Furthermore, these sources of energy are non-renewable, that is, they will not last forever. As their supplies dwindle, they will become too expensive, difficult to retrieve, and will also have a damaging impact on the environment.

As well as the continuation of developing countries, the traditional philosophy of planning that takes the centrality of the decision as an asset. while the new philosophy is decentralization, which believes that the socio-economic planning process inherently collaborative process must be subject to the views of the competencies of planning and specialized planning as well as the beneficiary and have discussion and dialogue on the basis of the availability of information and data and not on the basis of jurisprudence and personal experience on trial or error. Moreover the failure to involve the public and private sectors remain the planning unsuccessful and not useful.

\section{Research Significance}

This research highlights the importance of planning which is the first function of management and is the basis for building state institutions, and it is the public policy of any State that the State institutions have to implement, and that the success of any country is a result of the planning for the future. However the failure of many plans in developing countries was a result of not formulating sound information and data, that impact the implementation and to take advantage of them. The importance of research lies in raising the level of planning that comes from its importance:

1. The development of any nation is measured by the progress of the state in the development of its economic plans.

2. The level of development of society is determined by the quality of its business organizations resulting from the production of goods and services operations to satisfy the needs of the citizens which is a part of good planning.

3. The cost of living for the members of the country depends on the flexibility of the plan due to the availability of data and information, which in turn affect the efficiency and effectiveness of the performance and the degree of achieving the organizations objectives.

\section{Research Goals}

All states have a role in development, but this varies widely. This research aims to highlight the importance of the principle of planning and the success of this principle come from the proper position of the planning, which is the basis of building a sound, clear and comprehensive base of information and data, which in turn lead to the creation of a successful and viable plans. 


\section{Research Questions}

1. What kind of Changes happens in the plans when there are data and information on a broad base?

2. Has there been any positive results when developing countries focused on planning with data and information on a broad and integrated base?

3. What is the degree of benefit from the experiences of some countries in the structure of its economy models according to the plans on the basis of precise information and data base?

4. What are the positive lessons that can be learnt and pitfalls to be avoided from development experience of different countries?

\section{THE IMPORTANCE OF PLANNING IN ECONOMY DEVELOPMENT}

After the WWII, the importance of economic planning has emerged clearly as an important factor which can participate in the reconstruction and development of the destructed infrastructure because of the long war and to help in refreshing its economy again. The United States at that time has set forward its conditions to extend its economic grants according to Marshall Plan [14]. The plan was in operation for four years beginning April 8, 1948. The goals of the United States were to rebuild wardevastated regions, remove trade barriers, modernize industry, make Europe prosperous once more, and prevent the spread of communism.

This plan restored the confidence of the European people in the economic future of their own countries. This aid provided much needed money and materials that enabled Europeans to rebuild the continent's economy. For the United States, the Marshall Plan provided markets for American goods to be sold, created reliable trading partners, and supported the development of stable democratic governments in Western Europe [14].

A similar plan has been followed by the newly independent countries in Africa, Latin America and Middle East with a view to creating an encouraging environment and chances for the youth in particular, by making them stay and find significant employment at home rather than looking for work in Europe.

It worth noting that some people feel that the planning approach was associated with communist ideology. This is not accurate as the first ideas to the imperatives of planning emerged with the worsening economic crisis in Europe, which was called the Great Depression during the 1929-1930 and it was the longest and most severe depression ever experienced by the industrialized Western world. The problem begun with a tragic failure of stock-market prices on the New York Stock Exchange in October 1929. Throughout the subsequent three years stock prices in the United States sustained fall, till by late 1932 they had fallen to only about 20 percent of their value in 1929 [14].

\section{First Requirement: Defining Economic Planning and its Necessity}

Planning simply means deciding in advance what is to be done, when where, how and by whom it is to be done [4][5][6].

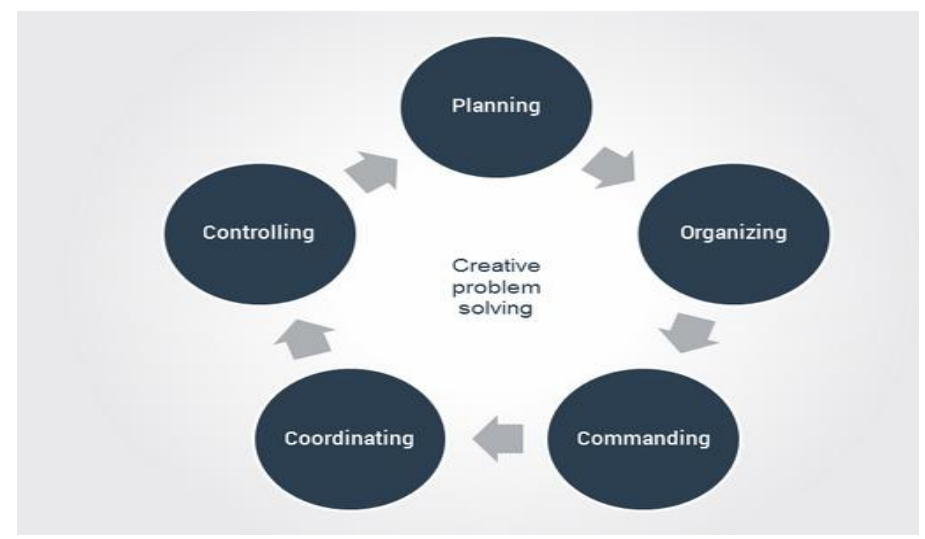

Figure1. Henri Fayol Management Functions

According to Henri Fayol [15], Planning is looking ahead, drawing up a good plan of action is the hardest of the five functions of management. This requires an active participation of the entire organization. With respect to time and implementation, planning must be linked to and coordinated on 
different levels. Managers must plan for future conditions, develop strategic objectives and secure the achievement of future goals. Therefore, managers must evaluate future contingencies affecting the organization, and shape the future operational and strategic landscape of the company. Planning must take the organization's available resources and flexibility of personnel into consideration as this will guarantee continuity [5][15].

According to Alford and Beatt [15][1], "Planning is the thinking process, the organized foresight, the vision based on fact and experience that is required for intelligent action."

According to Koontz and O' Donnell [15], "Planning is an intellectual process, conscious determination of course of action, the basing of decision on purpose, facts and considered estimates."

Planning bridges the gap from where we are to where we want to go. It includes the selection of objectives, policies, procedures and programs from among alternatives.

However, the Economic Planning and Development, is to identify a set of harmonized objectives to be achieved according to certain priorities, and during a specified period of time.

The concept of Strategic Planning has been defined in different ways [6][5]. Some scholars have emphasized formality or the extent to which planning documents exist others have concentrated on sophistication, meaning whether the plan is structured or not. Developed countries realize the importance and necessity of Strategic Planning Managers' awareness of the value of Strategic Planning has enhanced in developed countries. They feel that it is worth carrying out SP. Business schools and training institutions can play significant roles in this field. More emphasis must be placed on training programs that address the value of strategic planning and its merits, with special reference to its consequences. A substantial amount of evidence has emerged from the developed world, which indicates that strategic planning is associated positively with financial performance and negatively with failure rates [4][5][6].

Despite the lack of agreement by economists on a single definition of a special economic planning, it can be defined as the administrative, conscious and rational effort being made by society, state and individuals, which aims to identify, record and guiding the available economic resources, human, natural, and the organization of how to use them in order to ensure the achievement of the desired objectives during a specified period of time.

An important advantage of planning is that it makes effective and proper utilization of enterprise resources [8][6]. It identifies all such available resources and makes optimum use of these resources. An organization without planning is like a sailboat minus its rudder. Without planning, organization, are subject to the winds of organizational change. Planning is one of the most important and crucial functions of management. According to Koontz and O'Donnell, "Without planning business becomes random in nature and decisions become meaningless and adhoc choices."

\section{The Second Requirement: Methods and Uses of Planning}

Planning is not one method to solve all the problems and its uses does not have a single method to solve all the problems, and it is not confined to the economic system of a particular community, however is practiced in different ways under the various philosophies and political systems. For example there are the strategic, economic, mandatory indicative, central, tactical, operational and contingency planning...etc

In spite of the multiple forms of planning, however, some common characteristics which unite this administrative process, especially the look and the development of alternatives, and the presence of the target. The aim of the majority of plans to achieve two goals:

\section{- Anti-Cyclical Planning}

Economic planning is primarily anticyclical or developmental [16]. Anti-cyclical planning is generally limited to industrially advanced countries with strong private sectors and well-developed markets. The principal aim of anticyclical planning is to achieve, within the prevailing economic and social framework and the limits prescribed by the need to maintain economic stability, a level of effective demand which allows the fullest utilization to be made of capital stocks, labor force and other resources. Policies and measures adopted to attain plan objectives and targets operate largely through the market and demand is controlled mostly through monetary and fiscal measures[16]. 
Anticyclical planning also aims to increase the rate at which incomes grow. But it lets the private sector determine the direction of growth and it does not attempt to rationalize public investment for the purpose of accelerating the rate of growth. Since there are usually too many rather than too few projects, the problem is not to stimulate growth but to insure that the growth rate does not expand so much that it jeopardizes economic stability through inflation or balance of payments difficulties.

\section{- Development Planning}

Many places in Africa, Asia, the Middle East, Latin America, and the Caribbean face challenges of rapid population growth, resource scarcity, rural-urban migration, and severe poverty and socioeconomic inequality. Development planners focus on understanding these issues and opportunities and formulating appropriate interventions, and on achieving social justice and redistribution of development benefits [16][2][4].

Third Requirement: Steps and Requirements for Effective Development Planning

\section{A. Stages of Development Planning}

1. Setting a plan goal

2. Collecting data and information and develop hypotheses for planning.

3. Identify alternatives of plans

4. Implementation of the plan and follow up on its progress.

\section{B. The Effective Economic Development Planning Requirements}

For the Planning to achieve its objectives at a lower level of costs and achieving efficiency and effectiveness in a timely manner it requires the following [7][8]:

1. Not to exaggerate the allocation of available resources to implement the plan and do not exceed the acceptable level.

2. Planning scheduling timetable, identifying priority activities related to the completion of the plan and to facilitate the monitoring and follow-up implementation.

3. Taking into account the behavior, motives, needs of those carrying out the plan.

4. Specify a precise objectives to be achieved

5. The planning has to be easy to understand with all the relevant parties

6. The planning has to be flexible to the extent that leads to keep pace with changes in the internal and external environment surrounding.

7. It should be realistic planning and to suit the needs and realities of society.

8. Maintaining the confidentiality of planning when it is required to ensure the achievement of its objectives.

9. The acceptance of the principle of participation in goals, and any participation in the planning of those who are linked to the implementation of the plan, or study them, or have previous experience in the field of planning.

10. Study the implementing agency and its potential and history of successes and failures, before agreeing to implement the plan.

\section{ECONOMIC PLANNING AND ITS RELATIONSHIP TO INFORMATION DATABASE AND} STANDARD MODELS

\section{First Requirement: Data and Information Base and its Relation to Planning}

Decision-making on all the individual and collective levels should be based on the type of information, the more the information is correct, the more the decisions are sound and valid, and vice versa [9][10][1]. 
This information must come from the raw data on the variables representing the phenomenon being studied. For example, if we assume that Vi represents the independent variable and Yi is the used variable, so the study must be based on a theoretical model or standard equation of the regression line which is $y i=a+b x i$. Thus we begin this section by defining the concepts of data, information and standardized forms.

\section{Data}

Data is distinct information that has been translated into a form that is more convenient to move or process. It's an Information in raw or unorganized form (such as alphabets, numbers, or symbols) that's been collected by the researcher about the variables that surrounds the studied case. The data that is collected from a source is called a raw data [1][11].

\section{Information Analysis}

It is a raw data have been processed and analyzed using statistical methods, and displayed in the form of a chart or summarized in a number, such as the arithmetic mean or provide parameters for a statistical relationship in the regression analysis with the goal of discovering useful information.

\section{Information and Data Relationship with Planning}

The Planning process can be described as identifying the real needs using what is available from the data of the past and present activity. Thus any study won't be helpful if it's not based on adequate and correct data and information.

\section{The Role of the State in Economic Planning Process}

The historical fact is apparent in the developing countries whereby the economic success and failure of those countries is closely linked to success and failure of political leadership in guiding the development planning process. It's known that politics and economics are major ingredients in the recipe for a healthy economy in every country [9][11]. The politically stable countries are enjoying more economic growth than the politically unstable ones.

A government is really just a mechanism that makes collective decisions for a large number of citizens who have different preferences. Whereby the more successful those decisions the more economic growth can be noticed and verse versa.

First Requirement: The Role of the State's Obligation and Responsibility to Guide the Development Planning Process

The governments now understand that they have to provide a good economy to keep citizens content, and they realize that free-market economies work best. Then political openness becomes crucial to keep economies growth going. Economic development and political stability are deeply connected. On the one hand, the ambiguity associated with an unstable political situation may decrease economic growth and the pace of economic development. However, poor economic performance may result in government failure and political turbulence [11].

Many developing economies in third world countries suffer from corruption in numerous different sectors of their economies and this seriously weakens the economy. There are many forms of corruption, including the theft of public funds and misuse of overseas aid by other developed nations [9][11].

All countries have the great moral responsibilities and obligations to address economic and social issues such as human growth, literacy and eradicate poverty [12][13].

In most developing countries today, corruption is widespread and part of everyday life. Society has learned to live with it. The fight against corruption is necessary for a successful country. Third world countries may follow the example of some successful cases in taking serious steps in fighting corruption of developed and developing nations like in Europe and Asia. The spectacular growth of many economies in East Asia over the past 30 years has amazed the economics profession. The developmental states of Japan and the East Asian Newly Industrializing Countries (NICs) that are neither Communist nor laissez faire, but exhibit characteristics of both. Even the International Bank for Reconstruction and Development, acknowledged in its study of the East Asian countries, that in some cases interventions by governments to develop have resulted in the highest economic growth 
[4][7]. An example of that is the economy of Japan, Malaysia, and Singapore which is one of the most successful regional economies of the world. In modern nations, a high level of structural differentiation, functional specialization, and autonomy of the economic system from government is a major contributor to industrial-commercial growth and prosperity. The state plays an activist, rather than a minimalist, role; there is planning, but it is geared toward creating maximum competitive and comparative advantage for manufacturers within a market economy.

\section{The Second Requirement: Malaysian example with State Development Planning}

Malaysia is generally regarded as one of the most successful non-western countries to have achieved a relatively smooth transition to modern economic growth over the last century or so. To produce these economic miracles, the government of Malaysia controlled economic growth through the setting up planning visions. Since the late nineteenth century it has been a major supplier of primary products to the industrialized countries; tin, rubber, palm oil, timber, oil, liquified natural gas, etc. However, Prior to 1970 , the policies implemented were able to attain satisfactory growth, but they failed to improve equity or significantly eradicate poverty. Since the implementation of a new policy of planning, Malaysia has achieved growth, structural transformation, and poverty alleviation [4][7].

By 1990 the country had largely met the criteria for a Newly-Industrialized Country (NIC) status (30 percent of exports to consist of manufactured goods). Malaysian economy is one of the freest, most advanced, economical and investor-friendly in East Asia. The Malaysian story has been regarded a worthy model to be considered, especially countries with similar backgrounds. The Corruption Perceptions Index lists Malaysia as one of the least corrupt states in the world, along with Singapore. While the Asian economic crisis of 1997-98 slowed growth temporarily, the current plan, titled Vision 2020, aims to achieve a fully developed industrialized economy by that date.

The first is market led development that was applied between 1957 and 1970. When this was found inadequate, the state led development phase was introduced between 1971 and 1985. However, due to external factors, Malaysia had to move to the liberalisation and globalisation phase from 1986 onwards. The Malaysian government pursued laissez faire policies for industrial development, but intervened extensively to promote rural development and provide sound social and physical infrastructure [4][7][10].

In order to attain social cohesion through poverty eradication and social engineering, the Malaysian government has implemented several policies and programs. Since the incidence of poverty in Malaysia had always been predominantly rural, it was critical that rural-based poverty reduction and income improvement programs be implemented. Aside from a number of social safety net programs, the notable specific policies and programs that have the most impact on growth with equity are the following, which were implemented during the NEP period and beyond.

Education was given a central role as a strategy to modernize society, attain social goals, equalize opportunities and promote national unity. All the above factors have participated in the economic growth of Malaysia.

\section{CONCLUSION}

The development planning process is a mirror whereby the government and the state sees its image through what has been achieved and to be achieved for the future plans. All that is required for successful planning process is a sincere political guidelines which will manage the planning process. In addition, the basis for successful planning is the study of the real issues faced by country to take serious decisions and to put forward certain plans. However, the fact is that successful study based on fact-based data derived properly from an integrated information is the base for successful planning process. Because planning has become a modern-day necessity of life, practiced by all developed and developing countries on different levels. Thus, the countries that has future economic plans will be better and more successful than those that do not have any plans as planning nowadays is considered a strong social economic necessity. The government must be serious in implementing all the strategic reform initiatives. Accelerated implementation of productivity enhancing improvements to surge the quality of human capital and generate more competition in the economy will be key to secure a lasting place among the ranks of high-income economies. 


\section{REFERENCES}

[1] Noe, R. A., Hollenbeck, J. R., Gerhart, B., \& Wright, P. M. (2006). Human resource management: Gaining a competitive advantage.

[2] Blakely, E. J., \& Leigh, N. G. (2013). Planning local economic development. Sage.

[3] Oi, J. C. (1995). The role of the local state in China's transitional economy. The China Quarterly, 144, 1132-1149.

[4] Wade, R. (1990). Governing the market: Economic theory and the role of government in East Asian industrialization. Princeton University Press.

[5] Boserup, E., \& Kanji, N. (2007). Woman's role in economic development. Earthscan.

[6] Stimson, R. J., Stough, R. R., \& Roberts, B. H. (2006). Regional economic development: analysis and planning strategy. Springer Science \& Business Media.

[7] Francks, P., \& Francks, P. (2015). Japanese economic development: theory and practice. Routledge.

[8] Phillips, R., \& Pittman, R. (2014). An introduction to community development. Routledge.

[9] Li, M. H., Cui, L., \& Lu, J. (2014). Varieties in state capitalism: Outward FDI strategies of central and local state-owned enterprises from emerging economy countries. Journal of International Business Studies, 45(8), 980-1004.

[10] Carnoy, M., \& Shearer, D. (2016). Economic democracy: The challenge of the 1980s. Routledge.

[11] Reese, L. A., \& Staff, U. C. (2014). Local economic development policy: the United States and Canada. Routledge.

[12] Mallen, B. (2013). Marketing channels and economic development: a literature overview. International Journal of Physical Distribution \& Logistics Management.

[13] Leftwich, A. (1994). Governance, the State and the Politics of Development. Development and change, 25(2), 363-386.

[14] Hogan, M. J. (1987). The Marshall Plan: America, Britain and the Reconstruction of Western Europe, 1947-1952. Cambridge University Press.

[15] Golden Pryor, M., \& Taneja, S. (2010). Henri Fayol, practitioner and theoretician-revered and reviled. Journal of Management History, 16(4), 489-503.

[16] Taylor, V. (1999). A Quick Guide to Gender Mainstreaming in Development Planning. Commonwealth Secretariat. 